\title{
Novel missense mutation of SASH1 in a Chinese family with dyschromatosis universalis hereditaria
}

\author{
Lu Cao ${ }^{1,2,3,4,5 \dagger}{ }^{+}$, Ruixue Zhang ${ }^{1,2,3,4,5 \dagger}$, Liang Yong ${ }^{1,2,3,4,5}$, Shirui Chen ${ }^{1,2,3,4,5}$, Hui Zhang ${ }^{1,2,3,4,5}$, Weiwei Chen 1,2,3,4,5, \\ Qiongqiong $X u^{1,2,3,4,5}$, Huiyao Ge $e^{1,2,3,4,5}$, Yiwen Mao ${ }^{1,2,3,4,5}$, Qi Zhen ${ }^{1,2,3,4,5}$, Yafen $\mathrm{Yu}^{1,2,3,4,5}$, Xia Hu $\mathrm{u}^{1,2,3,4,5}$ and \\ Liangdan $\operatorname{Sun}^{1,2,3,4,5^{*}}$ (D)
}

\begin{abstract}
Background: Dyschromatosis universalis hereditaria (DUH) is a pigmentary dermatosis characterized by generalized mottled macules with hypopigmention and hyperpigmention. ABCB6 and SASH1 are recently reported pathogenic genes related to DUH, and the aim of this study was to identify the causative mutations in a Chinese family with DUH.

Methods: Sanger sequencing was performed to investigate the clinical manifestation and molecular genetic basis of these familial cases of DUH, bioinformatics tools and multiple sequence alignment were used to analyse the pathogenicity of mutations.

Results: A novel missense mutation, c.1529G >A, in the SASH1 gene was identified, and this mutation was not found in the National Center for Biotechnology Information Database of Short Genetic Variation, Online Mendelian Inheritance in Man, ClinVar, or 1000 Genomes Project databases. All in silico predictors suggested that the observed substitution mutation was deleterious. Furthermore, multiple sequence alignment of SASH1 revealed that the p.S510N mutation was highly conserved during evolution. In addition, we reviewed the previously reported DUH-related gene mutations in $\mathrm{SASH} 1$ and $A B C B 6$.
\end{abstract}

Conclusion: Although the affected family members had identical mutations, differences in the clinical manifestations of these family members were observed, which reveals the complexity of the phenotype-influencing factors in DUH. Our findings reveal the mutation responsible for DUH in this family and broaden the mutational spectrum of the SASH1 gene.

Keywords: $A B C B 6$ gene, Dyschromatosis universalis hereditaria, Mutation, SASH1 gene

\section{Background}

Dyschromatosis universalis hereditaria (DUH) is an infrequent hereditary dermatosis accompanied by generalized mottled macules with hypopigmention and hyperpigmention. This genodermatosis usually begins at birth

*Correspondence: ahmusld@163.com

${ }^{\dagger}$ Lu Cao and Ruixue Zhang have contributed equally to the work

${ }^{1}$ Department of Dermatology, the First Affiliated Hospital of Anhui

Medical University, Hefei, China

Full list of author information is available at the end of the article or in early childhood and affects almost the whole body; nails, hair, and teeth can even be involved. Some cases may be accompanied by systemic damage, such as deafness, visual impairment, and neurological symptoms.

DUH was first reported by Ichikawa and Hiraga in 1933. As a hereditary disorder, determining the causative gene is particularly important for the diagnosis and treatment of DUH. As early as 2003, Chinese scholars performed genome-wide screening in two DUH families from Henan and Yunnan for linkage analysis and 
confirmed that the gene associated with dominant dyschromatosis symmetrica hereditaria (DSH) maps to chromosome 6q24.2-q25.2 [1]. It is worth noting that Xing et al. diagnosed the family with DSH, while the results of subsequent studies suggested that the family should actually have been diagnosed with DUH [2]. In 2008, Stuhrmann et al. [3] discovered an autosomal-recessive inheritance associated with DUH region 12q21-q23 in the Arab population. In 2013, Zhang et al. identified a third DUH-related pathogenic region, 2q33.3-q36.13, and confirmed that ACBC6, located at 2q35, is the pathogenic gene of DUH [4].

Therefore, DUH can be divided into three types, DUH1 (Online Mendelian Inheritance in Man (OMIM) 127500), DUH2 (OMIM 612715) and DUH3 (OMIM 615402), based on the different linkage regions located in the 6q24.2-q25.2, 12q21q23 and 2q35 regions, respectively. DUH1 and DUH3 are inherited in an autosomal-dominant manner, while DUH2 is inherited in an autosomalrecessive manner. $A B C B 6$ and $S A S H 1$ [5] are recently reported pathogenic genes related to DUH. We collected data from a Chinese family with DUH with a novel missense mutation in SASH1 and reviewed published literature on mutations in SASH1 related to pigmentation abnormalities.

\section{Methods}

\section{Clinical findings and diagnosis}

We recruited a family with DUH with autosomal-dominant pigmentary disorder characteristics. The family pedigree is shown in Fig. 1, in which III6 was the proband. The proband was a 22-year-old male with lesions that varied in size and pigmentation throughout the body. The macules were isolated and were not associated with pain or itching; macules on both upper limbs and the back were more serious, whereas the palms, soles and mucosa were free of macules (Fig. 2a, b). The proband developed symptoms at the age of 4 , with scattered spots appearing first on his face and hands and then gradually spreading to other parts of the body, such as the trunk and extremities. Macules no longer changed after approximately 15 years of age. The proband reported that the skin became slightly red after sun exposure and the skin lesions slightly worsened. Because the patient's skin colour was light, hypopigmentation spots were not obvious.

His mother (II3) and cousin (III9) underwent a similar clinical process to that of the proband, and macules spread over their whole body. Dark brown pigmentation was diffusely distributed across the proband's cousin's face and limbs, while the trunk showed mild symptoms (Fig. 2c, d). The lesions of the proband's mother were more typical, with obviously generalized hyperpigmentation spots mixed with hypopigmentation spots in a reticular pattern on the hands and back (Fig. 2e, f). The proband's sister (III5), father (II4), uncle (II9) and cousin (III11) were unaffected.

\section{Sanger sequencing}

We collected detailed clinical data and pictures. Venous blood samples from family members II3, II4, II9, III5, III6, III9 and III11 were collected using EDTA anticoagulant tubes. DNA was extracted in accordance with the kit procedure (Sigma) and stored at $-80{ }^{\circ} \mathrm{C}$. To identify the presence and identity of mutations in candidate genes verified by target sequencing, Sanger sequencing of polymerase chain reaction (PCR) amplicons from genomic DNA was used. Twenty-five pairs of specially designed primers were used to cover all exons of SASH1, and these primers were designed by online Primer3 software (http://bioinfo.ut.ee/primer3-0.4.0/) and are illustrated in Additional file 1. Then, the DNA samples were amplified by PCR using HotStarTaq polymerase (TAKARA).

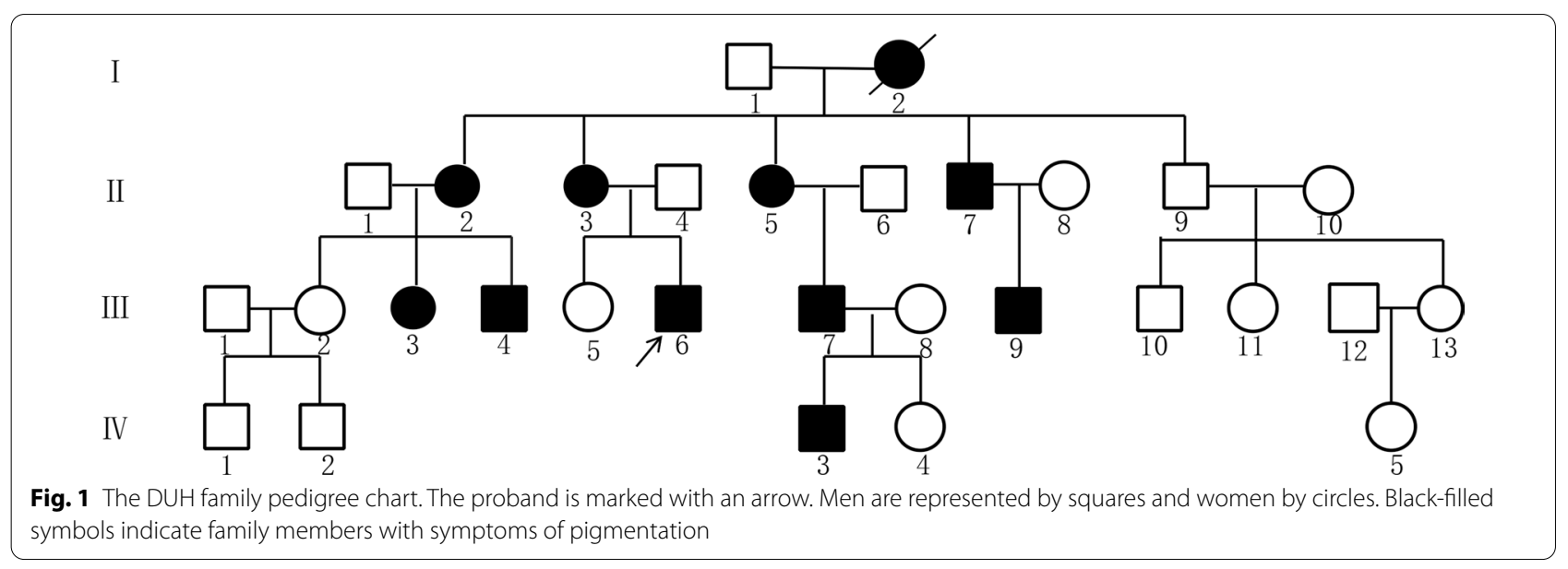



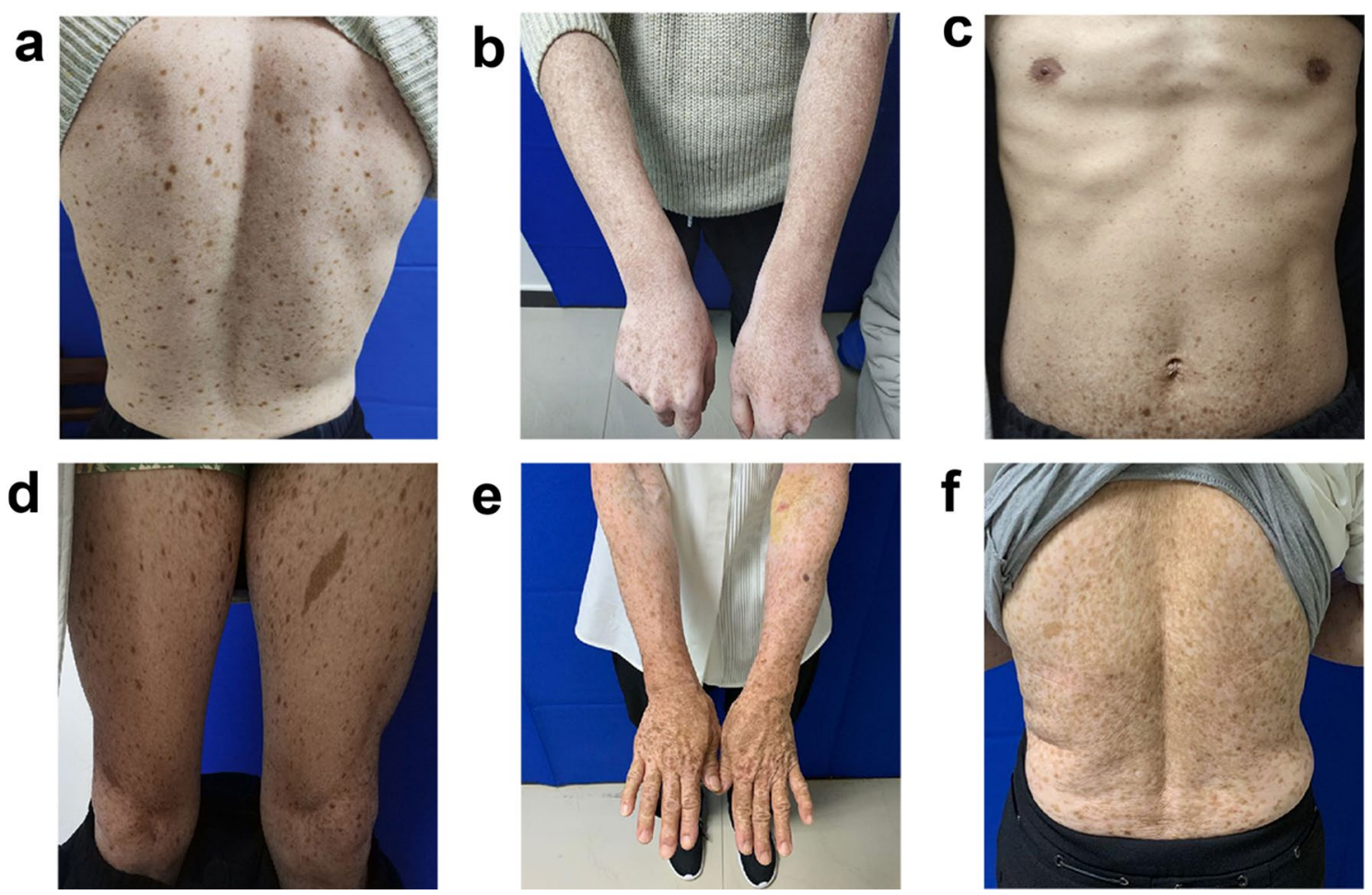

e

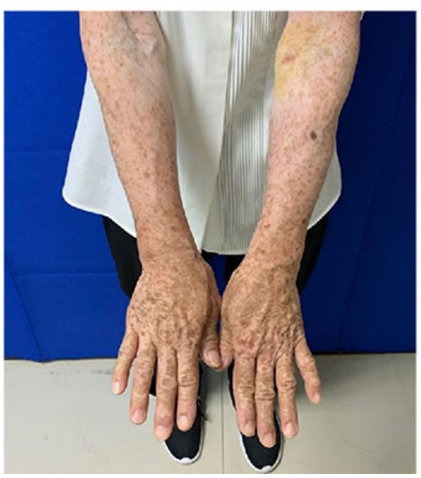

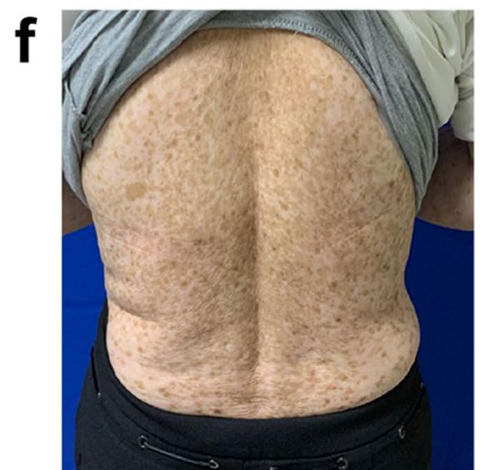

Fig. 2 a, b Mottled hypo- and hyper-pigmented macules on the trunk and limbs in the proband. $\mathbf{c}$, $\mathbf{d}$ Cutaneous manifestations of the proband's cousin. Dark-brown pigmentation was diffusely distributed on his abdomen and limbs and more severely distributed on the extremities. $\mathbf{e}, \mathbf{f}$ Cutaneous manifestations of the proband's mother. Generalized hyperpigmentation spots mixed with hypopigmentation spots in a reticular pattern on their hands and back

PCR products were purified by SAP (Promega) and Exo I (Epicentre) and then sequenced with a BigDye3.1 kit (ABI). The sequencing products were analysed by an ABI3730XL DNA Analyzer, and the results were analysed by PolyPhred software and confirmed by manual inspection.

\section{Results}

According to the Sanger sequencing results, we identified a previously unreported heterozygous missense mutation [(hg19) chr6:g.148852762G >A/c.1529G >A/p.S510N] in exon 13 of the SASH1 gene (NM_015278) in family members II3, III6, and III9 (Fig. 3), and this mutation was not present in the other four unaffected individuals (II4, II9, III5, and III11; the Sanger sequencing traces are shown in Additional file 2). This variant was the only one that cosegregated perfectly with the phenotype in this family, and the variant was not found in the National Center for Biotechnology Information Database of Short Genetic Variation (dbSNP) (https://www.ncbi.nlm.nih.gov/snp/), OMIM (https://www.omim.org/), ClinVar (https://www. ncbi.nlm.nih.gov/clinvar/), or The 1000 Genomes Project (1000G) (https://www.1000genome.org) databases. The presence of this variant resulted in an amino acid substitution from serine to asparagine (p.Ser510Asn). The p.S510N substitution occurs within the highly conserved SLY region. Moreover, all in silico predictors suggested that the observed substitution mutation is deleterious: SIFT (deleterious, score $=0.017 \mathrm{http}$ : / $/$ sift.bii.astar.edu.sg), PolyPhen (probably damaging, score $=1$ http://genetics.bwh.harvard.edu/pph2), and MutationTaster (disease-causing, $\mathrm{p}=1 \mathrm{http} / / \mathrm{www}$.mutationta ster.org). Multiple sequence alignment was performed on SASH1 for seven diverse vertebral species (Homo sapiens, Mus musculus, Cavia porcellus, Chlorocebus sabaeus, Pan paniscus, Canis lupus familiaris, Bos taurus) using Clustal (https://www.ebi.ac.uk/Tools/msa/clustalo/), and the results indicated that codon 510 is highly conserved during evolution and has functional importance (Fig. 4).

\section{Discussion}

When we reviewed the case of this family, we found a higher proportion of affected individuals in the second generation than expected for a heterozygous mutation. Therefore, we hypothesize that the mutation carried by the proband's grandmother may be homozygous, which means that II9 may also carry the pathogenic mutation. The fact that no features of DUH were observed in II9 
III9

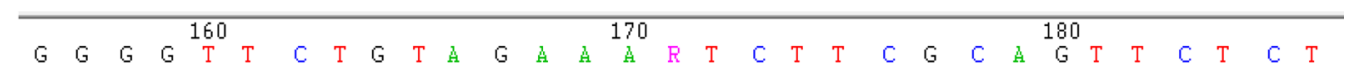

III6
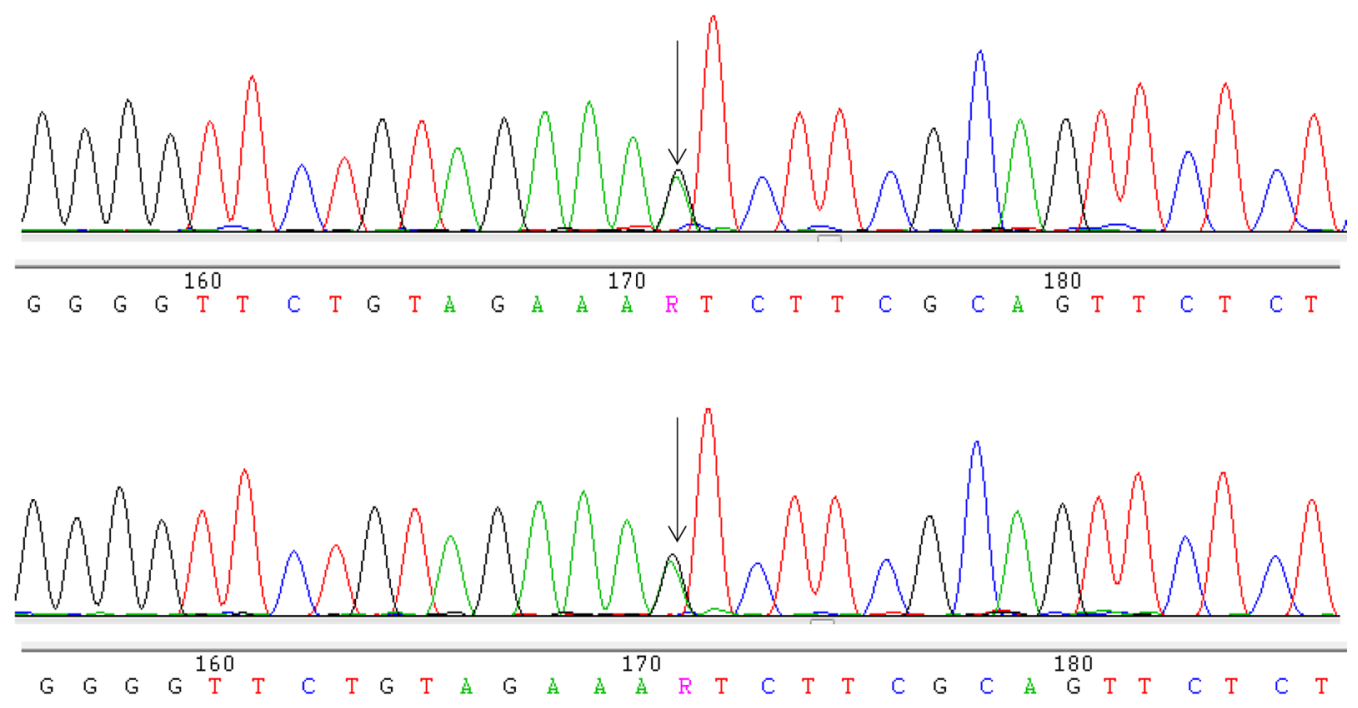

II 3

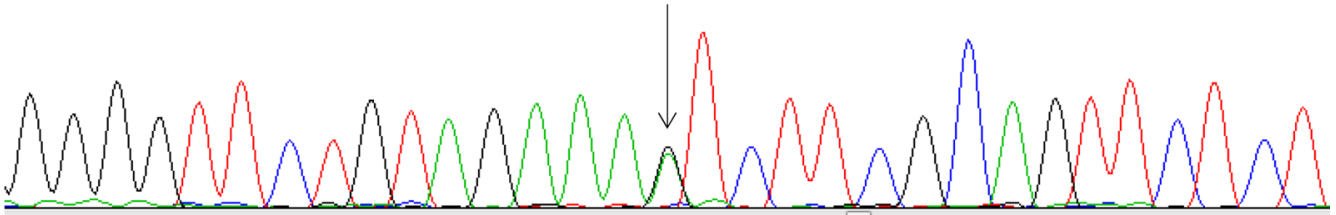

Fig. 3 A missense mutation, c.1529G >A (p.Ser510Asn), in SASH1 was found in the affected family members (II3, III6, and III9)

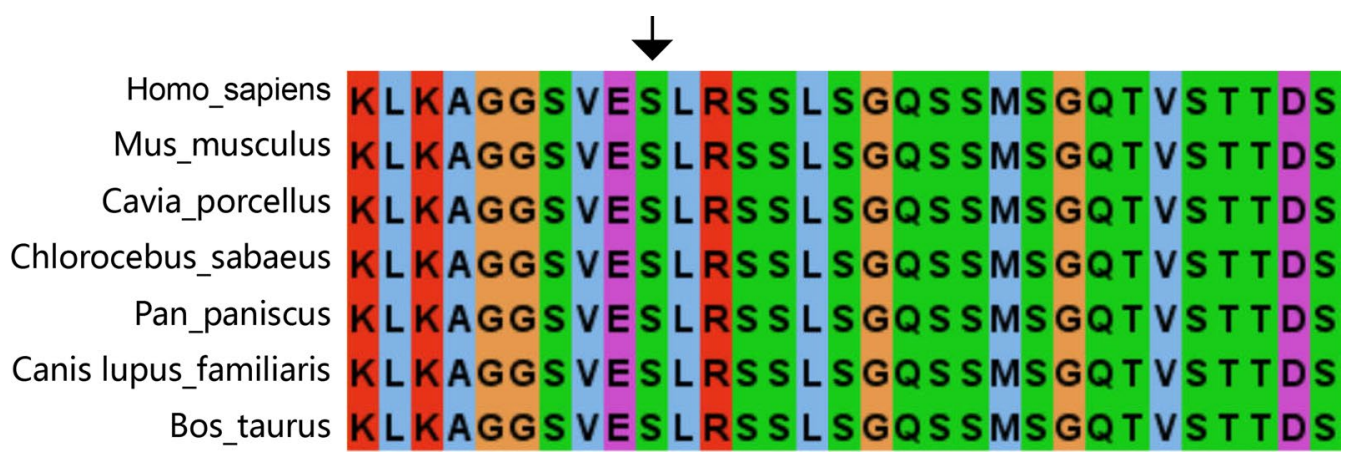

Fig. 4 Multiple alignment of partial sequences of SASH1 from seven diverse vertebrate species performed with Clustal showing that the p.S510N (shown with an arrow) is highly conserved during evolution

(Additional file 3) may be related to reduced penetrance, which is not uncommon in genetic disease and often explains why individuals with disease-causing mutations fail to express the phenotype of the disease [6]. The patient reported that he was not breastfed because his mother died shortly after giving birth to him, which may be the reason for incomplete penetrance. We conducted Sanger sequencing to verify whether the possible pathogenic variant was present in II9, but as shown in the sequencing trace, II9 did not carry the mutation. Therefore, the causes of the unusual prevalence of affected 
individuals in the second generation remain poorly defined.

The SASH1 gene, which is located at 6q2e4.3, contains an SLY domain, an SH3 domain, and two SAM domains. The SASH1 gene was originally thought to work as a tumour suppressor for breast cancer [7] and colon cancers [8] and has been demonstrated to have a crucial regulatory role in tumorigenesis. Subsequently, the role of SASH1 in pigmentation disorders has been continuously explored, as it participates in the DUH process by modulating melanocyte transepithelial migration through the Gas-SASH1-IQGAP1-E-cadherin signalling pathway [5] or, with the help of novel p53/ $\alpha-\mathrm{MSH} / \mathrm{POMC} / \mathrm{G \alpha s} /$ SASH1 crosstalk, p53 regulates the ERK1/2/CREB cascade and then causes hyperpigmentation [9]. Recently, in vivo studies on $S A S H 1$ function were investigated in a heterozygous mouse model in which the SASH1 c.1654T > G (p.Tyr551Asp, Y551D) mutation was knocked in. $\mathrm{Xu}$ et al. pointed out that SASH1 regulates the expression of Mitf in the nucleus by acting as a scaffold molecule that participates in the assembly of the SASH1MITF molecular complex and promotes the hyperpigmentation phenotype in the pathogenesis of DUH and other dermatoses related to abnormal pigmentation [10].

To date, 17 heterogeneous missense mutations in SASH1 have been confirmed to be associated with pigmentation disorders, among which eight mutations result in DUH $[5,11,12]$ and nine are responsible for multiple lentiginous phenotypes [13-16]; furthermore, the missense mutation c.1849G $>$ A was reported to result in a loss of pigmentation with palmoplantar keratoderma and skin carcinoma [17]. The distribution of all mutations in the protein domain of SASH1 inducing pigmentary anomalies is shown in Fig. 5, and the information related to the mutations is shown in Table 1. Most mutations are located in the SLY domain, which is highly conserved and seen as a hotspot mutation region [13]. Zhou et al. [5] first identified three missense mutations in SASH1, c.2126T>G (p.Tyr551Asp), c.2019T>C (p.Leu515Pro), c.2000G >A (p.Glu509Lys). In 2016, Chinese scholars recruited a family with nine affected members who manifested irregular light-brown- to dark-brown-pigmented spots over the whole body; the remaining skin was uniformly hypopigmented, and a fourth missense mutation, c.1761C $>$ G (p.Ser587Arg), was identified. Moreover, Zhong et al. [11] reported two unrelated DUH pedigrees with novel missense mutations in SASH1. Proband 1 was a 25-year-old female born with normal skin pigmentation. At the age of 3, the freckle-like macules gradually spread to her trunk, face, neck and limbs, with accentuation on sun-exposed areas intermingled with hypopigmented spots. Proband 2 was a 42-year-old male who shared similar clinical manifestations with an earlier onset time. Analysis revealed the presence of the c.1784T>C (p.M595T) and c.1651T>C (p.Y551H) missense mutations in the $S A S H 1$ gene. The most recent case was described by Wu et al. [12], who described the case of a 6-year-old girl with generalized hyperpigmented spots, and her family members shared similar symptoms. After genetic analysis, a novel missense mutation, c.1553A $>$ C, was discovered.

In addition to DUH, nine missense mutations in SASH1 (p.S513R, p.L511Kfs"21, p.S519N, p.S507A, p.I586M, p.S531Y, p.R644W, p.T525R and p.S516I) were reported to be associated with the lentiginous phenotype. Multiple lentigines are known to be characteristic of generalized lentiginosis, which is an autosomal-dominant genetic disease with abnormal pigmentation that can be associated with cardiovascular diseases, mental retardation, neurological deafness and other abnormalities. The common

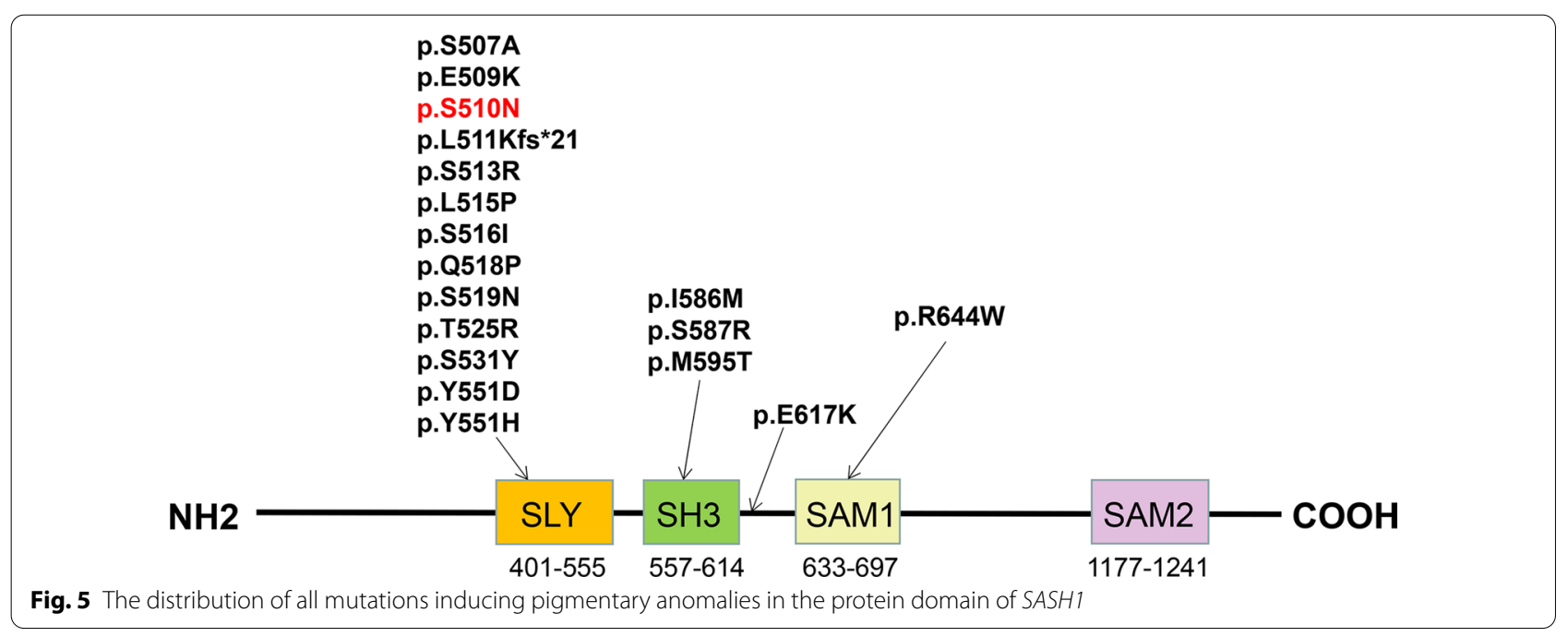


Table 1 SASH1 mutations associated with pigmentation disorders

\begin{tabular}{|c|c|c|c|c|c|c|c|}
\hline Number & Gene & Clinical phenotypes & Mode of inheritance & Onset age & Nucleotide change & Amino acid change & References \\
\hline 1 & SASH1 & $\begin{array}{l}\text { Dyschromatosis uni- } \\
\text { versalis hereditaria }\end{array}$ & - & - & c. $2000 \mathrm{G}>\mathrm{A}$ & p.Glu509Lys & Zhou et al. [5] \\
\hline 2 & SASH1 & $\begin{array}{l}\text { Dyschromatosis uni- } \\
\text { versalis hereditaria }\end{array}$ & - & - & c.2019T>C & p.Leu515Pro & Zhou et al. [5] \\
\hline 3 & SASH1 & $\begin{array}{l}\text { Dyschromatosis uni- } \\
\text { versalis hereditaria }\end{array}$ & - & - & c. $2126 \mathrm{~T}>\mathrm{G}$ & p.Tyr551Asp & Zhou et al. [5] \\
\hline 4 & SASH1 & $\begin{array}{l}\text { Dyschromatosis uni- } \\
\text { versalis hereditaria }\end{array}$ & $\begin{array}{l}\text { Autosomal-dominant } \\
\text { inheritance }\end{array}$ & $<1$ year & c. $1761 C>G$ & p.Ser587Arg & $\begin{array}{l}\text { Chinese Journal of } \\
\text { Dermatology }\end{array}$ \\
\hline 5 & SASH1 & $\begin{array}{l}\text { Dyschromatosis uni- } \\
\text { versalis hereditaria }\end{array}$ & $\begin{array}{l}\text { Autosomal-dominant } \\
\text { inheritance }\end{array}$ & 3 years & C. $1784 \mathrm{~T}>\mathrm{C}$ & p.Met595Thr & Zhong et al. [11] \\
\hline 6 & SASH1 & $\begin{array}{l}\text { Dyschromatosis uni- } \\
\text { versalis hereditaria }\end{array}$ & $\begin{array}{l}\text { Autosomal-dominant } \\
\text { inheritance }\end{array}$ & 7 months & C. $1651 \mathrm{~T}>\mathrm{C}$ & p.Tyr $551 \mathrm{His}$ & Zhong et al. [11] \\
\hline 7 & SASH1 & $\begin{array}{l}\text { Dyschromatosis uni- } \\
\text { versalis hereditaria }\end{array}$ & $\begin{array}{l}\text { Autosomal-dominant } \\
\text { inheritance }\end{array}$ & 2 years & C. $1553 \mathrm{~A}>\mathrm{C}$ & p.Gln518Pro & Wu et al. [12] \\
\hline 8 & SASHI & $\begin{array}{l}\text { Dyschromatosis uni- } \\
\text { versalis hereditaria }\end{array}$ & $\begin{array}{l}\text { Autosomal-dominant } \\
\text { inheritance }\end{array}$ & 4 years & C. $1529 \mathrm{G}>\mathrm{A}$ & p.Ser510Asn & Our present study \\
\hline 9 & SASHI & $\begin{array}{l}\text { Lentiginous pheno- } \\
\text { type }\end{array}$ & $\begin{array}{l}\text { Autosomal-dominant } \\
\text { inheritance }\end{array}$ & 1 year & C.1556G $>A$ & p.Ser519Asn & Shellman et al. [13] \\
\hline 10 & SASH1 & $\begin{array}{l}\text { Lentiginous pheno- } \\
\text { type }\end{array}$ & $\begin{array}{l}\text { Autosomal-dominant } \\
\text { inheritance }\end{array}$ & 3 years & c. $1537 A>C$ & p.Ser513Arg & Zhang et al. [14] \\
\hline 11 & SASH1 & $\begin{array}{l}\text { Lentiginous pheno- } \\
\text { type }\end{array}$ & Sporadic & - & c.1527_1530dupAAGT & p.Leu511Lysfs*21 & Zhang et al. [14] \\
\hline 12 & SASH1 & $\begin{array}{l}\text { Lentiginous pheno- } \\
\text { type }\end{array}$ & $\begin{array}{l}\text { Autosomal-dominant } \\
\text { inheritance }\end{array}$ & 18 months & c.1519T>G & p.Ser507Ala & Wang et al. [15] \\
\hline 13 & SASH1 & $\begin{array}{l}\text { Lentiginous pheno- } \\
\text { type }\end{array}$ & Sporadic & 14 months & C. $1758 C>G$ & p.lle586Met & Yuta Araki et al. [16] \\
\hline 14 & SASH1 & $\begin{array}{l}\text { Lentiginous pheno- } \\
\text { type }\end{array}$ & $\begin{array}{l}\text { Autosomal-dominant } \\
\text { inheritance }\end{array}$ & 2 years & c. $1592 C>A$ & p.Ser531Tyr & Yuta Araki et al. [16] \\
\hline 15 & SASH1 & $\begin{array}{l}\text { Lentiginous pheno- } \\
\text { type }\end{array}$ & $\begin{array}{l}\text { Autosomal-dominant } \\
\text { inheritance }\end{array}$ & 3 years & C. $1930 C>T$ & p.Arg644Trp & Yuta Araki et al. [16] \\
\hline 16 & SASH1 & $\begin{array}{l}\text { Lentiginous pheno- } \\
\text { type }\end{array}$ & Sporadic & 2 years & c. $1574 C>G$ & p.Thr525Arg & Yuta Araki et al. [16] \\
\hline 17 & SASH1 & $\begin{array}{l}\text { Lentiginous pheno- } \\
\text { type }\end{array}$ & Sporadic & 8 months & c. $1547 \mathrm{G}>\mathrm{T}$ & p.Ser516lle & Yuta Araki et al. [16] \\
\hline 18 & SASH1 & $\begin{array}{l}\text { Dyschromatosis-uni- } \\
\text { versalis-hereditarian- } \\
\text { like pigmentation }\end{array}$ & $\begin{array}{l}\text { Autosomal-recessive } \\
\text { inheritance }\end{array}$ & 1 year & c. $1849 \mathrm{G}>\mathrm{A}$ & p.Glu617Lys & Courcet et al. [17] \\
\hline
\end{tabular}

pathogenic genes reported thus far include PTPN11, $B R A F$ and RAF1 [18-20]; therefore, whether these two diseases have overlapping virulence genes or, due to similar phenotypes, these cases were misdiagnosed are worth further discussion.

$A B C B 6$ was first determined to be the causative gene of DUH by Zhang et al. when genome-wide linkage analysis and exome sequencing was completed; c.1067T>C (p.Leu356Pro), c.508A>G (p.Ser170Gly) and c.1736G >A (p.Gly579Glu) were identified in the DUH family or sporadic cases [4]. To date, nine mutations have been discovered in $A B C B 6$ associated with DUH. The other six mutations were c.1663C $>$ A (p.Gln555Lys), c.459delC (p.Trp154Glyfs"96), c.1358C >T (p.Ala453Val), c.964A >C (p.Ser322Lys), c.1270T>C (p.Tyr424His), and c.2017A>G
(p.Thr673Ala) [21-25]. Furthermore, a novel missense mutation in $A B C B 6$ (p.N467S) was reported in a case of xeroderma pigmentosum $\mathrm{C}$ combined with $\mathrm{DUH}-$ like pigmentation [26]. Wu et al. [12] pointed out that, compared with the disease caused by $S A S H 1$ mutation, the disease caused by $A B C B 6$ mutation showed more typical manifestations, such as generalized mottled hyperpigmented macules mixed with hypopigmented macules arranged in a reticular pattern. In contrast, diseases caused by $S A S H 1$ mutations are more likely to be confused with generalized lentiginosis. We have different views on diseases caused by SASH1 mutations, and we present case examples of our views. As shown above, although the mutation in the proband was the same as that in his mother and cousin, their clinical 
manifestations were different. Possibly due to the light colour of his skin, the proband had milder hypopigmentation than his mother and cousin. We hypothesized that because clinical manifestations are influenced by skin colour, age, and other environmental factors, such as ultraviolet (UV) exposure, the correlation of genotype and phenotype in patients with DUH needs to be further investigated.

\section{Conclusions}

In conclusion, we found a novel mutation, c.1529G $>A$ of SASH1 in a family with DUH. This novel mutation broadens the mutational spectrum of this gene. As further research on the genetics of DUH is carried out and more pathogenic genes and mutation sites are discovered, a further understanding of the genetic characteristics of DUH will be obtained, providing the basis for the clinical implementation of gene therapy for DUH.

\section{Abbreviations}

DUH: Dyschromatosis universalis hereditaria; EDTA: Ethylenediaminetetraacetic acid; PCR: Polymerase chain reaction; dbSNP: National Center for Biotechnology Information Database of Short Genetic Variation; OMIM: Online Mendelian Inheritance in Man; 1000G: The 1000 Genomes Project; SIFT: Scale invariant feature transform; UV: Ultraviolet.

\section{Supplementary Information}

The online version contains supplementary material available at https://doi. org/10.1186/s12920-021-01014-w.

Additional file 1. The primer of SASH1 gene.

Additional file 2. Cutaneous manifestation of the proband's uncle (II9).

Additional file 3. The Sanger sequencing trace of unaffected individuals (II4, II9, III5, III11).

\section{Acknowledgements}

We thank all patients for their participation in our study.

\section{Authors' contributions}

LDS was responsible for this study and provided suggestions on the study design and data analysis. LC and RXZ wrote the manuscript and collected blood samples. SRC and $\mathrm{HZ}$ collected the clinical information and extracted DNA. XH, QQX, WWC, LY and YFY conducted Sanger sequencing. QZ, YWM and HYG performed the data analysis. All authors contributed to the study and approved the final manuscript. All authors read and approved the final manuscript.

\section{Funding}

Leading Talents of the National Ten Thousand Talents Program, Clinical Medicine Discipline Construction Project of Anhui Medical University (2021lcxk008), and the Research Fund of Anhui Institute of Translational Medicine (ZHYX2020A005) provided support throughout the whole process of study design, clinical data collection and reagent procurement.

\section{Availability of data and materials}

The datasets analyzed during the present study are available from Zenodo (number: 4898895, https://zenodo.org/record/4898895\#.YLnm1Mij7RQ). The novel variant has been submitted to ClinVar database (accession number: SCV001548229, https://www.ncbi.nlm.nih.gov/clinvar/variation/1048561/).
The relevant datasets links were as follows: dbSNP (https://www.ncbi.nlm.nih. gov/snp/), OMIM (https://www.omim.org/), ClinVar (https://www.ncbi.nlm.nih. gov/clinvar/), and 1000G (http://www.1000genomes.org/).

\section{Declarations}

Ethics approval and consent to participate

The study was conducted under protocols approved by the Clinical Research Ethics Committee of Anhui Medical University and adhered to the tenets of the Declaration of Helsinki. All of the participants in the study were over 18 years old, and written informed consent was obtained from the participants.

\section{Consent for publication}

Written informed consent for the publication of clinical details and clinical images was obtained from all of the participants.

\section{Competing interests}

The authors declare no conflict of interest.

\section{Author details}

${ }^{1}$ Department of Dermatology, the First Affiliated Hospital of Anhui Medical University, Hefei, China. ${ }^{2}$ Institute of Dermatology, Anhui Medical University, Hefei, China. ${ }^{3}$ Key Laboratory of Dermatology, Anhui Medical University, Ministry of Education, Hefei, China. ${ }^{4}$ Inflammation and Immune Mediated Diseases Laboratory of Anhui Province, Hefei, China. ${ }^{5}$ Anhui Provincial Institute of Translational Medicine, Hefei, China.

Received: 24 December 2020 Accepted: 11 June 2021

Published online: 26 June 2021

\section{References}

1. Xing QH, Wang MT, Chen XD, Feng GY, Ji HY, Yang JD, et al. A gene locus responsible for dyschromatosis symmetrica hereditaria (DSH) maps to chromosome 6q24.2-q25.2. Am J Hum Genet. 2003;73(2):377-82.

2. Miyamura Y, Suzuki T, Kono M, Inagaki K, Ito S, Suzuki N, et al. Mutations of the RNA-specific adenosine deaminase gene (DSRAD) are involved in dyschromatosis symmetrica hereditaria. Am J Hum Genet. 2003;73(3):693-9.

3. Stuhrmann M, Hennies HC, Bukhari IA, Brakensiek K, Nurnberg G, Becker $C$, et al. Dyschromatosis universalis hereditaria: evidence for autosomal recessive inheritance and identification of a new locus on chromosome 12q21-q23. Clin Genet. 2008;73(6):566-72.

4. Zhang C, Li D, Zhang J, Chen X, Huang M, Archacki S, et al. Mutations in ABCB6 cause dyschromatosis universalis hereditaria. J Invest Dermatol. 2013;133(9):2221-8

5. Zhou D, Wei Z, Deng S, Wang T, Zai M, Wang H, et al. SASH1 regulates melanocyte transepithelial migration through a novel Gas-SASH1IQGAP1-E-Cadherin dependent pathway. Cell Signal. 2013;25(6):1526-38.

6. Cooper DN, Krawczak M, Polychronakos C, Tyler-Smith C, KehrerSawatzki H. Where genotype is not predictive of phenotype: towards an understanding of the molecular basis of reduced penetrance in human inherited disease. Hum Genet. 2013;132(10):1077-130.

7. Zeller C, Hinzmann B, Seitz S, Prokoph H, Burkhard-Goettges E, Fischer J, et al. SASH1: a candidate tumor suppressor gene on chromosome 6q24.3 is downregulated in breast cancer. Oncogene. 2003;22(19):2972-83.

8. Rimkus C, Martini M, Friederichs J, Rosenberg R, Doll D, Siewert JR, et al. Prognostic significance of downregulated expression of the candidate tumour suppressor gene SASH1 in colon cancer. Br J Cancer. 2006;95(10):1419-23.

9. Zhou D, Kuang Z, Zeng X, Wang K, Ma J, Luo H, et al. p53 regulates ERK1/2/CREB cascade via a novel SASH1/MAP2K2 crosstalk to induce hyperpigmentation. J Cell Mol Med. 2017;21(10):2465-80.

10. Xu Z, Li Y, Wang D, Wu D, Wang J, Chen L, et al. Mutated SASH1 promotes Mitf expression in a heterozygous mutated SASH1 knockin mouse model. Int J Mol Med. 2020;46(3):1118-34. 
11. Zhong WL, Wang HJ, Lin ZM, Yang Y. Novel mutations in SASH1 associated with dyschromatosis universalis hereditaria. Indian J Dermatol Venereol Leprol. 2019;85(4):440.

12. Wu N, Tang L, Li X, Dai Y, Zheng X, Gao M, et al. Identification of a novel mutation in SASH1 gene in a Chinese family with dyschromatosis universalis hereditaria and genotype-phenotype correlation analysis. Front Genet. 2020;11:841.

13. Shellman YG, Lambert KA, Brauweiler A, Fain P, Spritz RA, Martini M, et al SASH1 is involved in an autosomal dominant lentiginous phenotype. J Invest Dermatol. 2015;135(12):3192-4.

14. Zhang J, Cheng R, Liang J, Ni C, Li M, Yao Z. Lentiginous phenotypes caused by diverse pathogenic genes (SASH1 and PTPN11): clinical and molecular discrimination. Clin Genet. 2016;90(4):372-7.

15. Wang J, Zhang J, Li X, Wang Z, Lei D, Wang G, et al. A Novel de novo mutation of the SASH1 gene in a Chinese family with multiple lentigines. Acta Derm Venereol. 2017;97(4):530-1.

16. Araki Y, Okamura K, Saito T, Matsumoto K, Natsuga K, Nishimoto J, et al. Five novel mutations in SASH1 contribute to lentiginous phenotypes in Japanese families. Pigment Cell Melanoma Res. 2021;34(2):174-8.

17. Courcet JB, Elalaoui SC, Duplomb L, Tajir M, Rivière JB, Thevenon J, et al. Autosomal-recessive SASH1 variants associated with a new genodermatosis with pigmentation defects, palmoplantar keratoderma and skin carcinoma. Eur J Hum Genet. 2015;23(7):957-62.

18. Faienza MF, Giordani L, Ferraris M, Bona G, Cavallo L. PTPN1 1 gene mutation and severe neonatal hypertrophic cardiomyopathy: what is the link? Pediatr Cardiol. 2009;30(7):1012-5

19. Sarkozy A, Carta C, Moretti S, Zampino G, Digilio MC, Pantaleoni F, et al. Germline BRAF mutations in Noonan, LEOPARD, and cardiofaciocutaneous syndromes: molecular diversity and associated phenotypic spectrum. Hum Mutat. 2009;30(4):695-702.
20. Pandit B, Sarkozy A, Pennacchio LA, Carta C, Oishi K, Martinelli S, et al. Gain-of-function RAF1 mutations cause Noonan and LEOPARD syndromes with hypertrophic cardiomyopathy. Nat Genet. 2007;39(8):1007-12.

21. Cui YX, Xia XY, Zhou Y, Gao L, Shang XJ, Ni T, et al. Novel mutations of $A B C B 6$ associated with autosomal dominant dyschromatosis universalis hereditaria. PLoS ONE. 2013;8(11):e79808.

22. Lu C, Liu J, Liu F, Liu Y, Ma D, Zhang X. Novel missense mutations of ABCB6 in two Chinese families with dyschromatosis universalis hereditaria. J Dermatol Sci. 2014;76(3):255-8.

23. Liu JW, Sun J, Vano-Galvan S, Liu FX, Wei XX, Ma DL. Differential diagnosis of two Chinese families with dyschromatoses by targeted gene sequencing. Chin Med J. 2016;129(1):33-8.

24. Liu H, Li Y, Hung KK, Wang N, Wang C, Chen X, et al. Genome-wide linkage, exome sequencing and functional analyses identify $A B C B 6$ as the pathogenic gene of dyschromatosis universalis hereditaria. PLoS ONE. 2014;9(2):e87250.

25. Zhong W, Pan Y, Shao Y, Yang Y, Yu B, Lin Z. Atypical presentation of dyschromatosis universalis hereditaria with a novel ABCB6 mutation. Clin Exp Dermatol. 2019:44(3):e58-60.

26. Masaki T, Nakano E, Okamura K, Ono R, Sugasawa K, Lee MH, et al. A case of xeroderma pigmentosum complementation group $\mathrm{C}$ with diverse clinical features. Br J Dermatol. 2018;178(6):1451-2.

\section{Publisher's Note}

Springer Nature remains neutral with regard to jurisdictional claims in published maps and institutional affiliations.
Ready to submit your research? Choose BMC and benefit from:

- fast, convenient online submission

- thorough peer review by experienced researchers in your field

- rapid publication on acceptance

- support for research data, including large and complex data types

- gold Open Access which fosters wider collaboration and increased citations

- maximum visibility for your research: over $100 \mathrm{M}$ website views per year

At BMC, research is always in progress.

Learn more biomedcentral.com/submissions 